\title{
$\mathrm{J}$

\section{A Metal-Organic Framework-Based Material for Electrochemical Sensing of Carbon Dioxide}

Jeremiah J. Gassensmith, ${ }^{\dagger, \S, \perp}$ Jeung Yoon Kim, ${ }^{\|, \perp}$ James M. Holcroft, ${ }^{\dagger}$ Omar K. Farha, ${ }^{, \neq}$

J. Fraser Stoddart, ${ }^{* \dagger}$ Joseph T. Hupp, ${ }^{\ddagger}$ and Nak Cheon Jeong*,ll

${ }^{\dagger}$ Department of Chemistry, Northwestern University, Evanston, Illinois 60208, United States

${ }^{\ddagger}$ Department of Chemistry and International Institute for Nanotechnology, Northwestern University, Evanston, Illinois 60208, United States

${ }^{\S}$ Department of Chemistry, University of Texas at Dallas, Richardson, Texas 75080, United States

"Department of Emerging Materials Science, Daegu Gyeongbuk Institute of Science and Technology (DGIST), Daegu 711-873, Korea

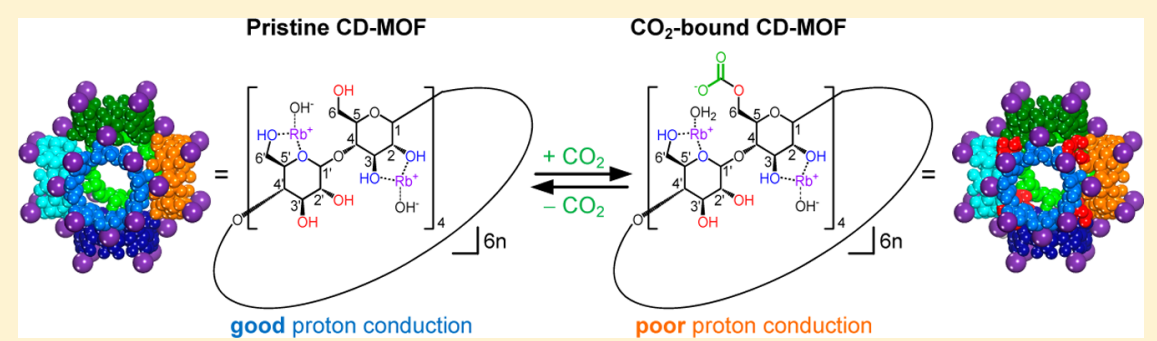

ABSTRACT: The free primary hydroxyl groups in the metal-organic framework of CDMOF-2, an extended cubic structure containing units of six $\gamma$-cyclodextrin tori linked together in cube-like fashion by rubidium ions, has been shown to react with gaseous $\mathrm{CO}_{2}$ to form alkyl carbonate functions. The dynamic covalent carbon-oxygen bond, associated with this chemisorption process, releases $\mathrm{CO}_{2}$ at low activation energies. As a result of this dynamic covalent chemistry going on inside a metal-organic framework, $\mathrm{CO}_{2}$ can be detected selectively in the atmosphere by electrochemical impedance spectroscopy. The "as-synthesized" CDMOF-2 which exhibits high proton conductivity in pore-filling methanolic media, displays a $\sim 550$-fold decrease in its ionic conductivity on binding $\mathrm{CO}_{2}$. This fundamental property has been exploited to create a sensor capable of measuring $\mathrm{CO}_{2}$ concentrations quantitatively even in the presence of ambient oxygen.

\section{INTRODUCTION}

The detection of carbon dioxide, a highly oxidized and largely inert gas, has proven difficult within mixtures of multiple gases owing to the presence of competing gas such as oxygen, carbon monoxide and water vapor, all of which are far more chemically active. ${ }^{1}$ It stands to reason, therefore, that the clear benefits of having robust and inexpensive devices to provide a quantitative analysis of $\mathrm{CO}_{2}$ concentrations in admixture with other gases provides more than enough impetus for the continued development of such devices. Much of the present sensing technology depends largely upon spectroscopic methods ${ }^{2}$ which become unreliable when the mixture ${ }^{2 a, 3}$ of gases contain spectroscopically similar resonances. Alternative methods, such as semiconducting field effect transistors ${ }^{2 a, b}$ (FETs), and semiconductive oxide sensors operate ${ }^{4}$ constantly at temperatures in excess of $200{ }^{\circ} \mathrm{C}$ (upward of $800{ }^{\circ} \mathrm{C}$ ) making them both power-hungry and potential ignition sources in areas with flammable or explosive gases. ${ }^{1}$ As an alternative, we have investigated the possibility for metal-organic frameworks (MOFs) to act as platforms for sensing analytes at relatively low temperatures.
Not so long ago, we communicated the discovery ${ }^{5}$ of a new $\gamma$-cyclodextrin-derived material called CDMOF-2 which exhibits strong but reversible binding of carbon dioxide. Although we were able to demonstrate ${ }^{5 b}$ rather crudely a colorimetric response of CDMOF-2 in the presence of $\mathrm{CO}_{2}$ by taking advantage of the unique chemistry which occurs within this highly porous material, this response is by no means sufficient for practical quantitative analysis. This highly porous material belongs to a rapidly growing family of MOFs, crystalline materials ${ }^{6}$ structured chemically with building blocks-typically clusters of metal ions (components of the nodes) and rigid organics ligands (components of the extendable structural frameworks). MOFs are well regarded for their highly ordered nanoporosity, large internal surface area and postsynthetic modifiability. Accordingly, MOFs have been evaluated as potential nanoporous materials for applications in chemical separations, ${ }^{7}$ gas adsorption, ${ }^{8}$ heterogeneous catalysis, ${ }^{9}$ ion exchange, ${ }^{10}$ drug delivery, ${ }^{11}$ and sensing. ${ }^{4 c, 12}$ While these

Received: January 26, 2014

Published: May 14, 2014 

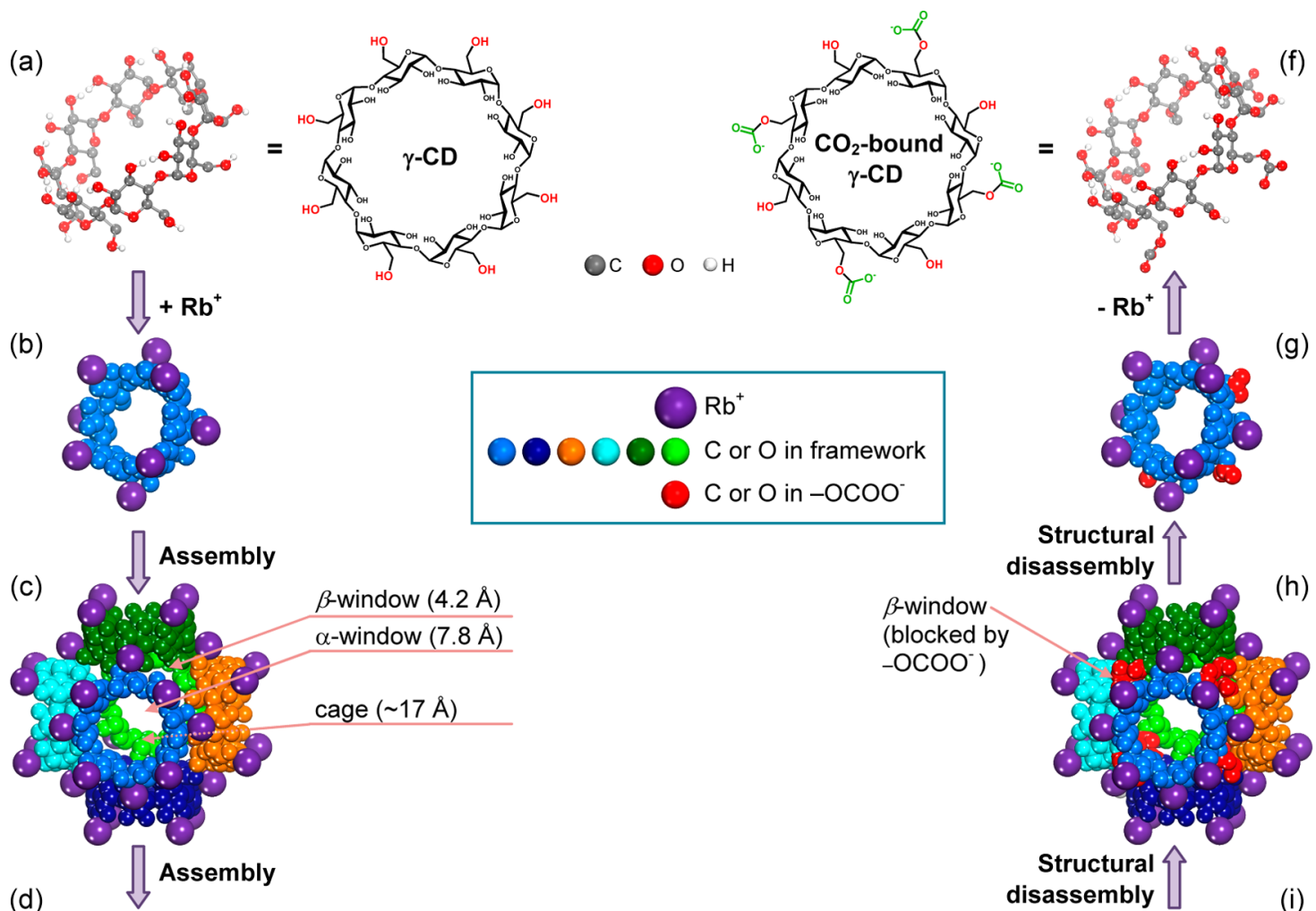

(d)

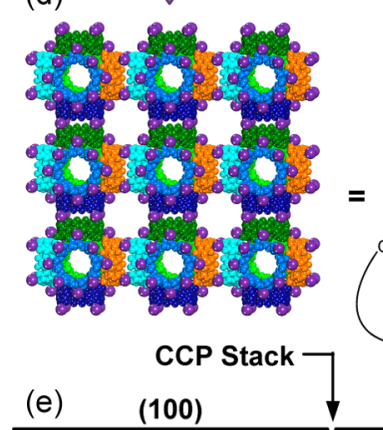

$(k)$
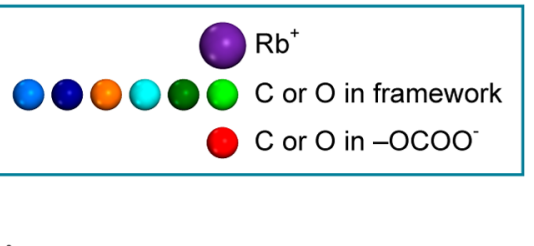

Structural $\uparrow$ disassembly

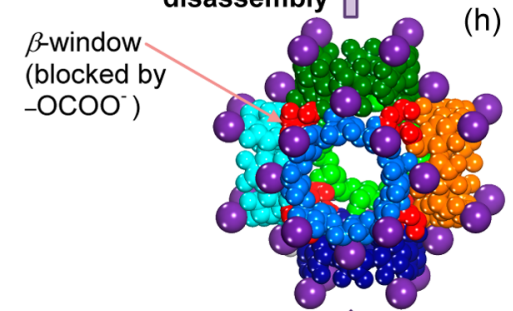
$\left.\begin{array}{r}\text { Structural } \\ \text { disassembly }\end{array}\right\}$

(i)

(h)

(I)

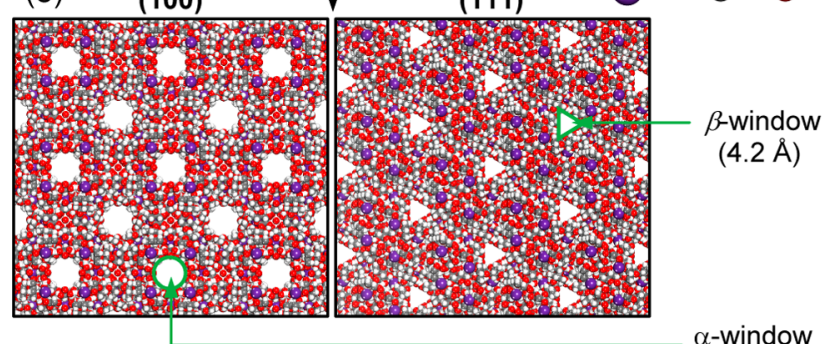

(7.8 A)

Figure 1. (a) Structural formula of $\gamma$-cyclodextrin $\left(\gamma\right.$-CD). (b) $\mathrm{Rb}^{+}$-coordinated $\gamma$-CD $\left[\left(\mathrm{Rb}^{+}\right)_{4}(\gamma-\mathrm{CD})\right]$. (c) $\left[\left(\mathrm{Rb}^{+}\right)_{4}(\gamma-\mathrm{CD})\right]_{6}$ unit in which the six $\gamma$ $\mathrm{CD}$ rings forming the sides of the cube are portrayed in different colors. $(\mathrm{d})\left[\left(\mathrm{Rb}^{+}\right)_{4}(\gamma-\mathrm{CD})\right]_{6 n}$ assembled in a planar fashion. (e) Space-filling representation of the CDMOF-2 crystal structure viewed down the 100 and 111 axes, and $(\mathrm{f}-\mathrm{j})$ In silico simulated schematic representations of $\mathrm{CO}_{2}$-bound CDMOF-2 structures as counterparts of $(\mathrm{a}-\mathrm{e})$. Hydrogen atoms only bound to carbon atoms in (a) and (f) and all of hydrogen atoms in $(\mathrm{b}-\mathrm{e}$ and $\mathrm{g}-\mathrm{j})$ are omitted for the sake of clarity. ( $\mathrm{k}$ and $\mathrm{l}$ ) Schematic diagram illustrating the equilibrium proposed to exist during the chemisorption of $\mathrm{CO}_{2}$ by CDMOF-2, expressed in the context of the structural formula of one of the four repeating maltosyl units present in a single $\gamma$-CD torus.

materials have proven to be suitable for a host of applications, there are few examples of MOFs utilizing ionic conduction ${ }^{13}$ as a means of chemical detection. For instance, it is surprising that, while MOFs are receiving a lot of attention as a method for $\mathrm{CO}_{2}$ sequestration, ${ }^{5 \mathrm{~b}, 7 \mathrm{a}, 14}$ to the best of our knowledge, there has been only one report of colorimetric sensing ${ }^{5 \mathrm{~b}}$ and no reports of electrochemical sensing of $\mathrm{CO}_{2}$ by MOFs. Indeed, only one has been reported for ion-conduction-based sensing, ${ }^{12 \mathrm{~g}}$ but it is just for detection of $\mathrm{H}_{2} \mathrm{O}$ rather than $\mathrm{CO}_{2}$. Ionic conductivity, as its name implies, depends upon the response of free ions within a bulk material. While this methodology would typically have no applicability in sensing chemical species that are not easily ionized, we have found that a pair of unique attributions of CDMOF-2, namely a very high concentration of free hydroxyl groups and the rapid reactivity of $\mathrm{CO}_{2}$ to form alkyl carbonic acids within the framework, 
produces a viable candidate to detect $\mathrm{CO}_{2}$ within mixtures of other, typically more reactive gases. Here, we present a method to detect carbon dioxide within $\mathrm{CO}_{2} / \mathrm{N}_{2}$ and $\mathrm{CO}_{2} /$ Air mixtures utilizing these attributes.

To this end, we have employed electrochemical impedance spectroscopy to measure the changes in proton conductivity as $\mathrm{CO}_{2}$ levels are altered incrementally around a sample of CDMOF-2. The data show the "as-synthesized" CDMOF-2 displays an approximately 550-fold change downward in its ionic conductivity upon binding to $\mathrm{CO}_{2}$, more than sufficient to produce a quantitative analysis of the atmospheric content of $\mathrm{CO}_{2}$.

\section{RESULTS AND DISCUSSION}

The majority of MOFs that have been designed for the selective uptake of $\mathrm{CO}_{2}$ have not exhibited reversible chemisorptiondesorption of carbon dioxide. Recently, however, we have elucidated $^{5 \mathrm{~b}, \mathrm{~d}}$ a mechanism by which a particular metal-organic framework, CDMOF-2, can store $\mathrm{CO}_{2}$ reversibly by forming labile covalent bonds on the framework. CDMOF-2 can be prepared by reaction of $\gamma$-cyclodextrin $[\gamma$-CD, see Figure $1 \mathrm{a}$ and Section $S 1$ in the Supporting Information] and rubidium hydroxide $(\mathrm{RbOH})$ at room temperature in aqueous methanol (or ethanol). $\gamma$-CD is a cyclic oligosaccharide composed of eight $\alpha$-D-glucopyranosyl residues linked 1,4 to each other. $\mathrm{Rb}^{+}$ cations bind with $\gamma$-CD tori by coordinating (Figure $1 \mathrm{~b}$ ) to some of the ring oxygen atoms together with some of the secondary and primary hydroxyl groups at C-2, C-3, and C-6 on the glucopyranosyl rings. The coordination sphere round a particular $\mathrm{Rb}^{+}$cation is satisfied by eight oxygen atoms from four different $\gamma$-CD tori. See Section S2 in the Supporting Information. This coordination geometry gives rise to a unit cell for CDMOF-2 (Figure 1c), composed of six $\gamma$-CD tori and $24 \mathrm{Rb}^{+}$cations forming a cubic cage inside of which there exists a $\sim 17 \AA$ diameter void with two kinds of windows: a large circular one ( $\alpha$-windows) of diameter $7.8 \AA$ and a smaller triangular-shaped one ( $\beta$-windows) that is $4.2 \AA$ from the apex to the opposite side of the triangle. Body-centered-cubic (bcc) close packing of the unit cells produces a framework with the larger circular $\alpha$-windows and the smaller triangular-shaped $\beta$ windows aligned, respectively, along the 100 and 111 axes in the crystal. ${ }^{13} \mathrm{C}$ NMR Spectroscopic investigations revealed that infusion of $\mathrm{CO}_{2}$ into the extended framework of CDMOF-2 results in covalent bonding of the $\mathrm{CO}_{2}$ to the noncoordinated free primary hydroxyl groups, forming alkyl carbonic acid (CA) functions on the $\gamma$-CD tori to yield CA-CDMOF-2 (Figure 1). On the basis of these observations, we have simulated ${ }^{15}$ the crystal structure of CA-CDMOF-2 to reveal the consequences of $\mathrm{CO}_{2}$ chemisorption along both the 100 and 111 axes (Figure $1 \mathrm{e}, \mathrm{j})$.

Generally, MOFs containing hydroxyl functional groups in their frameworks have been found to release protons into their nanopores or nanochannels with relatively low activation energies and thereby exhibit proton conduction. ${ }^{13 e-g}$ In a systematic investigation of the ionic conductivity of CDMOF-2, we examined the "as-synthesized" version of CDMOF-2 and a $\mathrm{CO}_{2}$ gas-infused (Figures 1 and 2) species, CA-CDMOF-2, with methanol or $n$-hexane as a pore-filling solvent. See Supporting Information Section S8. Key to the study is the role of the alkyl CA formed by $\mathrm{CO}_{2}$-binding. On the basis of the greater acidity of the carbonic acids relative to that of the primary alcohols, we expected that the $\mathrm{CO}_{2}$-infused CACDMOF-2 would show higher conductivity than pristine (a) CDMOF-2

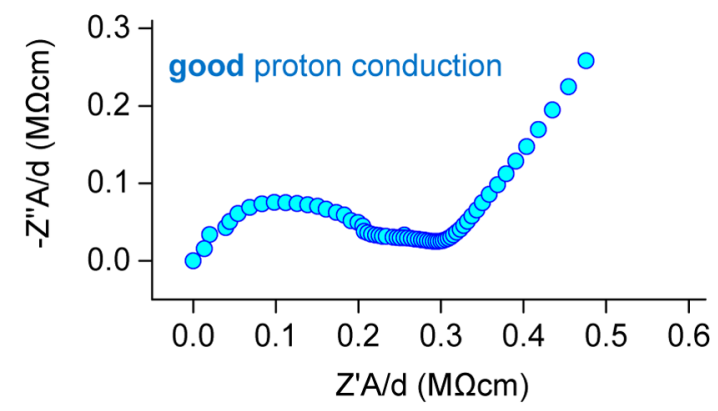

(b) CA-CDMOF-2

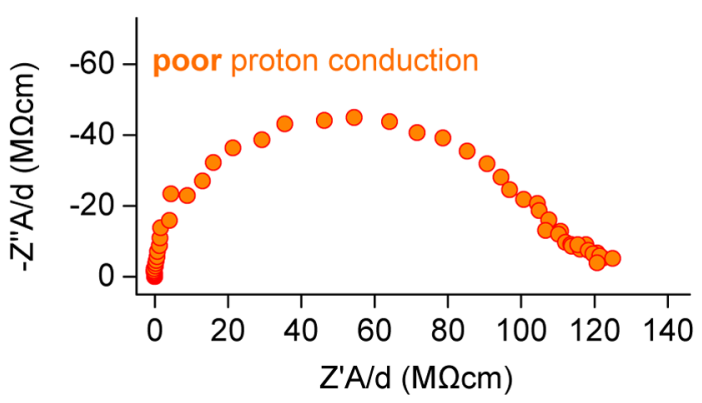

Figure 2. Impedance spectra of (a) a pristine CDMOF-2 and (b) $\mathrm{CO}_{2}$-infused CDMOF-2 samples following exposure to methanol vapor at room temperature.

CDMOF-2. Contrary to our expectations, we found that CDMOF-2 exhibits a 550-fold higher conductivity compared to that exhibited by CA-CDMOF-2 (see Figure 2 and Table 1). The conductivity of pristine CDMOF-2 was measured to be $\sim 4.8 \mu \mathrm{S} \mathrm{cm} \mathrm{cm}^{-1}$, while CA-CDMOF-2 is only $9 \mathrm{nS} \mathrm{cm}{ }^{-1}$. We attribute this observation tentatively to the blockage of the hydrophilic, triangular-shaped $\beta$-windows with carbonates as the reaction proceeds (Figure $1 \mathrm{j}$ ). These $\beta$-windows are the sole location of all uncomplexed, primary alcohol functions and, consequently, the place where carboxylation occurs primarily.

The tests were conducted under ambient air (ca. 35\% humidity). Dry conditions, however, increase the sensitivity: for instance, we have observed that high humidity decreases the sensitivity by a factor of ca. 5. See Section S9 in Supporting Information.

An attractive property of CDMOF-2 is the high degree of reversibility found in the chemisorption of $\mathrm{CO}_{2}$. This

Table 1. Conductivities of CDMOF-2 Samples Before and After Exposure to Gas-Phase $\mathrm{CO}_{2}$ for $5 \mathrm{~min}$ in Various $\mathrm{CO}_{2}$ Concentrations

\begin{tabular}{crrrrr} 
& \multicolumn{5}{c}{$\sigma\left(\mathrm{nS} \mathrm{cm}^{-1}\right)$} \\
\cline { 2 - 6 } $\mathrm{CO}_{2}$ concd $(\%)^{a}$ & sample 1 & sample 2 & sample 3 & avg. & ratio \\
0 & 4740 & 4569 & 5095 & 4801 & 550 \\
10 & 1069 & 1129 & 1248 & 1149 & 130 \\
20 & 228 & 198 & 223 & 216 & 24 \\
30 & 115 & 99 & 110 & 108 & 12 \\
40 & 63 & 49 & 57 & 57 & 6.5 \\
60 & 21 & 24 & 20 & 22 & 2.5 \\
90 & 11 & 12 & 10 & 11 & 1.2 \\
100 & 9 & 9 & 8 & 9 & 1.0
\end{tabular}

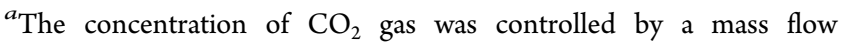
controller, diluting with nitrogen gas. 
reversibility, which occurs rapidly under very mild conditions, liberating the sequestered $\mathrm{CO}_{2}$, is important in the continuous reusability of CDMOF-2. To this end, the cyclic changes in conductivity by a pellet of CDMOF-2 as a result of undergoing multiple chemisorption-desorption experiments of $\mathrm{CO}_{2}$ were conducted. A pellet sample was prepared and the sample was exposed to $\mathrm{CO}_{2}$ gas $(99.8 \%$, bone dry) for chemisorption, tested, and then heated at $\sim 80{ }^{\circ} \mathrm{C}$ for desorption and tested again.

The conductivity of pristine CDMOF-2, which initially showed a high value, was decreased by a factor of $\sim 550$-fold after $\mathrm{CO}_{2}$ sorption, but was once again reinstated after $\mathrm{CO}_{2}$ desorption. This process is completely reversible (Figure 3) over many iterations with no degradation in performance.

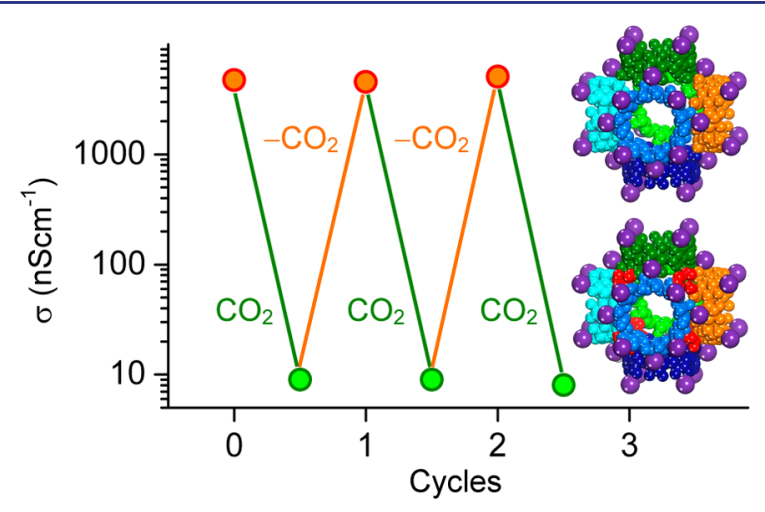

Figure 3. Cyclic change of conductivity of a CDMOF-2 sample following sequential $\mathrm{CO}_{2}$-sorption and desorption.

These promising initial experiments suggested to us that this MOF acts as a sensor for $\mathrm{CO}_{2}$ in the presence of air, from which no effort was made to exclude extraneous nitrogen or oxygen. With these results in hand, we wanted to examine whether the device displays gradual responses to the amount of $\mathrm{CO}_{2}$ present in a mixture with nitrogen. Thus, we tested the MOF and noted the conduction responses at various $\mathrm{CO}_{2}$ gas concentrations. The conductivity dropped down sharply (Figure 4) as the $\mathrm{CO}_{2}$ concentration was increased. Note the exponential scale of the $y$-axis. The slope shows an approximately exponential decay as the concentration is

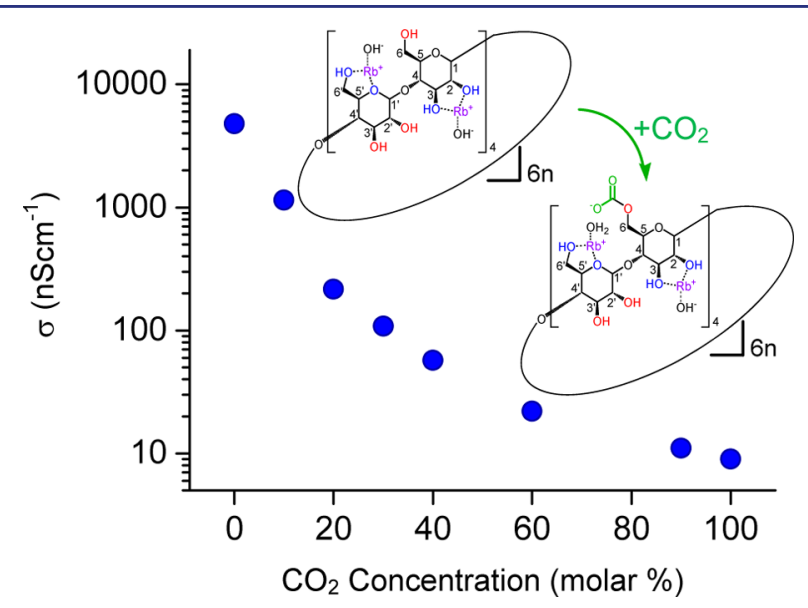

Figure 4. Exponential scale plot of average conductivity values in CDMOF-2 samples after their exposure for $5 \mathrm{~min}$ to $\mathrm{CO}_{2}$ gas, which was diluted with $\mathrm{N}_{2}$ in various concentrations. decreased with better sensitivity in the low $\mathrm{CO}_{2}$ concentration regime, compared with that at high concentrations (lower than $20 \%$, see Section S5 in the Supporting Information). On the basis of this observation, we speculate that the sensitivity will be affected by several factors including: (i) the rate of reaction associated with carboxylation, (ii) the diffusion rate of $\mathrm{CO}_{2}$ gas into pellets, (iii) the pellet thicknesses, and (iv) the exposure time of the sample to $\mathrm{CO}_{2}$ gas. On the basis of the assumption that the reaction rate associated with carboxylation is much faster than the $\mathrm{CO}_{2}$ diffusion rate, we used the slope as a criterion of sensitivity in the low $\mathrm{CO}_{2}$ concentration region, which is expected to be steep when the pellet thickness is thinner and/or the $\mathrm{CO}_{2}$ exposure time is longer. While a detailed investigation into pellet geometry is beyond the scope of this communication, we suspect from these observations that thin pellets or films will be more sensitive as a real time detector.

\section{CONCLUSIONS}

In summary, we have observed large ionic conductivity from the samples of "as-synthesized" CDMOF-2. The large drop ( $\sim 550$-fold) in the conductivity after $\mathrm{CO}_{2}$ infusion into these samples is attributed to an encumbrance in the motility of free protons. Additionally, we were able to show a sequential attenuation of the conductivity, together with incremental additions of $\mathrm{CO}_{2}$ in a mixture of other gases, providing a selective analysis of $\mathrm{CO}_{2}$ concentrations. The reduced conductivity of CA-CDMOF-2 can be ascribed to the loss of base (coordinated hydroxide) that can catalyze the deprotonation of the methanolic medium and blocking of the secondary $\beta$-windows that can significantly reduce mass transfer of the intermedium molecules. The sensitivity of the conductivity change is relatively high at low $\mathrm{CO}_{2}$ concentration, while the sensor, if fully reversible, follows the desorption of $\mathrm{CO}_{2}$. This research seeks to lay the foundation to address the need for an electrochemical means of sensing $\mathrm{CO}_{2}$ which comes, in part, from an emerging environmental requirement to monitor concentrations at and near high volume, emission pointsources, and from the limitations associated with present stateof-the-art technologies. The value added by using low cost and highly selective materials makes this device an attractive alternative for sensing carbon dioxide. This research has demonstrated that MOFs have a promising future in the field of quantitative sensing applications and that they are capable of showing much higher sensitivities than current methods. ${ }^{4 a, b}$

\section{ASSOCIATED CONTENT}

\section{S Supporting Information}

Experimental details, electrochemical impedance spectra, powder X-ray diffraction patterns, thermal gravimetric analysis, and elemental analysis. This material is available free of charge via the Internet at http://pubs.acs.org.

\section{AUTHOR INFORMATION}

\section{Corresponding Authors}

nc@dgist.ac.kr

o-farha@northwestern.edu

stoddart@northwestern.edu

\section{Author Contributions}

${ }^{\perp}$ J. J. Gassensmith and J. Y. Kim contributed equally.

Notes

The authors declare no competing financial interest. 


\section{ACKNOWLEDGMENTS}

This research is a part (Project 34-937) of the Joint Center of Excellence in Integrated Nano-Systems (JCIN) at King Abdulaziz City for Science and Technology (KACST) and Northwestern University (NU). The authors would like to thank both KACST and NU for their continued support of this research. J. T. Hupp and O. K. Farha gratefully acknowledge support from U.S. Department of Energy, Office of Science, Basic Energy Sciences (grant DE-FG2-08ER15967). N. C. Jeong gratefully acknowledges support from the Ministry of Science, ICT, and Future Planning (MSIP) of Korea, under the auspices of the Basic Science Research Program sponsored by the National Research Foundation (NRF 2013R1A1A1010254) and the DGIST R\&D Program (13BD-0403).

\section{REFERENCES}

(1) Liu, Y.; Tang, Y. H.; Barashkov, N. N.; Irgibaeva, I. S.; Lam, J. W. Y.; Hu, R. R.; Birimzhanova, D.; Yu, Y.; Tang, B. Z. J. Am. Chem. Soc. 2010, 132, 13951-13953.

(2) (a) Neethirajan, S.; Jayas, D. S.; Sadistap, S. Food Bioprocess Technol. 2009, 2, 115-121. (b) Hu, Y.; Tan, O. K.; Cao, W.; Zhu, W. Sensors for Chemical and Biological Applications; Ram, M. K., Bhethanabotla, V. R., Eds.; CRC Press: Boca Raton, FL, 2010; pp 1-42. (c) Cajlakovic, M.; Bizzarri, A.; Suppan, M.; Konrad, C.; Tscherner, M.; Ribitsch, V.; Beran, E.; Knez, I. Proc. IEEE Sens. 2009, 31-36. (d) Schaferling, M. Angew. Chem., Int. Ed. 2012, 51, 35323554

(3) (a) Lin, J. TrAC, Trends Anal. Chem. 2000, 19, 541-552. (b) Wolfbeis, O. S.; Weis, L. J.; Leiner, M. J. P.; Ziegler, W. E. Anal. Chem. 1988, 60, 2028-2030. (c) Hitchman, M. J.; Park, M. U.S. Patent. 6,365,022, 2002. (d) Safinya, K. A.; Tarvin, J. A. U.S. Patent. 4,994,671, 1991. (e) Tchakarov, B. J. D. R.; Forgan, S. W.; Fanini, O. N.; Hunziker, J. C.; Civarolo, M. F. U.S. Patent. 6,218,662, 2001. (f) Mills, A.; Hamilton, M. WO/9 105 252. 1991.

(4) (a) Capone, S.; Forleo, A.; Francioso, L.; Rella, R.; Siciliano, P.; Spadavecchia, J.; Presicce, D. S.; Taurino, A. M. J. Optoelectron. Adv. Mater. 2003, 5, 1335-1348. (b) Prim, A.; Pellicer, E.; Rossinyol, E.; Peiro, F.; Cornet, A.; Morante, J. R. Adv. Funct. Mater. 2007, 17, 2957-2963. (c) Kreno, L. E.; Leong, K.; Farha, O. K.; Allendorf, M.; Van Duyne, R. P.; Hupp, J. T. Chem. Rev. 2012, 112, 1105-1125.

(5) (a) Smaldone, R. A.; Forgan, R. S.; Furukawa, H.; Gassensmith, J. J.; Slawin, A. M. Z.; Yaghi, O. M.; Stoddart, J. F. Angew. Chem., Int. Ed. 2010, 49, 8630-8634. (b) Gassensmith, J. J.; Furukawa, H.; Smaldone, R. A.; Forgan, R. S.; Botros, Y. Y.; Yaghi, O. M.; Stoddart, J. F. J. Am. Chem. Soc. 2011, 133, 15312-15315. (c) Forgan, R. S.; Smaldone, R. A.; Gassensmith, J. J.; Furukawa, H.; Cordes, D. B.; Li, Q. W.; Wilmer, C. E.; Botros, Y. Y.; Snurr, R. Q.; Slawin, A. M. Z.; Stoddart, J. F. J. Am. Chem. Soc. 2012, 134, 406-417. (d) Wu, D.; Gassensmith, J. J.; Gouvea, D.; Ushakov, S.; Stoddart, J. F.; Navrotsky, A. J. Am. Chem. Soc. 2013, 135, 6790-6793.

(6) (a) Yaghi, O. M.; O’Keeffe, M.; Ockwig, N. W.; Chae, H. K.; Eddaoudi, M.; Kim, J. Nature 2003, 423, 705-714. (b) Ferey, G. Chem. Soc. Rev. 2008, 37, 191-214. (c) Horike, S.; Shimomura, S.; Kitagawa, S. Nat. Chem. 2009, 1, 695-704. (d) Farha, O. K.; Hupp, J. T. Acc. Chem. Res. 2010, 43, 1166-1175. (e) Cook, T. R.; Zheng, Y.R.; Stang, P. J. Chem. Rev. 2012, 113, 734-777.

(7) (a) Li, J. R.; Kuppler, R. J.; Zhou, H. C. Chem. Soc. Rev. 2009, 38, 1477-1504. (b) Lee, C. Y.; Bae, Y. S.; Jeong, N. C.; Farha, O. K.; Sarjeant, A. A.; Stern, C. L.; Nickias, P.; Snurr, R. Q.; Hupp, J. T.; Nguyen, S. T. J. Am. Chem. Soc. 2011, 133, 5228-5231. (c) Bhattacharya, B.; Dey, R.; Pachfule, P.; Banerjee, R.; Ghoshal, D. Cryst. Growth Des. 2013, 13, 731-739. (d) Das, M. C.; Guo, Q. S.; He, Y. B.; Kim, J.; Zhao, C. G.; Hong, K. L.; Xiang, S. C.; Zhang, Z. J.; Thomas, K. M.; Krishna, R.; Chen, B. L. J. Am. Chem. Soc. 2012, 134, 8703-8710. (e) He, Y. B.; Zhang, Z. J.; Xiang, S. C.; Fronczek, F. R.; Krishna, R.; Chen, B. L. Chem. Commun. 2012, 48, 6493-6495. (f) He, Y. B.; Zhou, W.; Krishna, R; Chen, B. L. Chem. Commun. 2012, 48, 11813-11831. (g) He, C. T.; Tian, J. Y.; Liu, S. Y.; Ouyang, G. F.; Zhang, J. P.; Chen, X. M. Chem. Sci. 2013, 4, 351-356.

(8) (a) Murray, L. J.; Dinca, M.; Long, J. R. Chem. Soc. Rev. 2009, 38, 1294-1314. (b) Farha, O. K.; Yazaydin, A. O.; Eryazici, I.; Malliakas, C. D.; Hauser, B. G.; Kanatzidis, M. G.; Nguyen, S. T.; Snurr, R. Q.; Hupp, J. T. Nat. Chem. 2010, 2, 944-948. (c) Furukawa, H.; Ko, N.; Go, Y. B.; Aratani, N.; Choi, S. B.; Choi, E.; Yazaydin, A. O.; Snurr, R. Q.; O’Keeffe, M.; Kim, J.; Yaghi, O. M. Science 2010, 329, 424-428. (d) Zhou, H. C.; Zhao, D.; Timmons, D. J.; Yuan, D. Q. Acc. Chem. Res. 2011, 44, 123-133.

(9) (a) Lee, J.; Farha, O. K.; Roberts, J.; Scheidt, K. A.; Nguyen, S. T.; Hupp, J. T. Chem. Soc. Rev. 2009, 38, 1450-1459. (b) Ma, L. Q.; Abney, C.; Lin, W. B. Chem. Soc. Rev. 2009, 38, 1248-1256.

(10) Min, K. S.; Suh, M. P. J. Am. Chem. Soc. 2000, 122, 6834-6840.

(11) (a) Horcajada, P.; Serre, C.; Vallet-Regi, M.; Sebban, M.; Taulelle, F.; Ferey, G. Angew. Chem., Int. Ed. 2006, 45, 5974-5978. (b) An, J.; Geib, S. J.; Rosi, N. L. J. Am. Chem. Soc. 2009, 131, 83768377. (c) Taylor-Pashow, K. M. L.; Rocca, J. D.; Xie, Z.; Tran, S.; Lin, W. J. Am. Chem. Soc. 2009, 131, 14261-14263. (d) Della Rocca, J.; Liu, D. M.; Lin, W. B. Acc. Chem. Res. 2011, 44, 957-968.

(12) (a) Zhao, B.; Chen, X.-Y.; Cheng, P.; Liao, D.-Z.; Yan, S.-P.; Jiang, Z.-H. J. Am. Chem. Soc. 2004, 126, 15394-15395. (b) Wong, K. L.; Law, G. L.; Yang, Y. Y.; Wong, W. T. Adv. Mater. 2006, 18, 10511054. (c) Chen, B.; Yang, Y.; Zapata, F.; Lin, G.; Qian, G.; Lobkovsky, E. B. Adv. Mater. 2007, 19, 1693-1696. (d) Rieter, W. J.; Taylor, K. M. L.; Lin, W. J. Am. Chem. Soc. 2007, 129, 9852-9853. (e) Chen, B.; Wang, L.; Zapata, F.; Qian, G.; Lobkovsky, E. B. J. Am. Chem. Soc. 2008, 130, 6718-6719. (f) Harbuzaru, B. V.; Corma, A.; Rey, F.; Atienzar, P.; Jordá, J. L.; García, H.; Ananias, D.; Carlos, L. D.; Rocha, J. Angew. Chem., Int. Ed. 2008, 47, 1080-1083. (g) Achmann, S.; Hagen, G.; Kita, J.; Malkowsky, I. M.; Kiener, C.; Moos, R. Sensors 2009, 9, 1574-1589. (h) Chen, B.; Wang, L.; Xiao, Y.; Fronczek, F. R.; Xue, M.; Cui, Y.; Qian, G. Angew. Chem., Int. Ed. 2009, 48, 500-503. (i) Harbuzaru, B. V.; Corma, A.; Rey, F.; Jordá, J. L.; Ananias, D.; Carlos, L. D.; Rocha, J. Angew. Chem., Int. Ed. 2009, 48, 6476-6479. (j) Xie, Z.; Ma, L.; deKrafft, K. E.; Jin, A.; Lin, W. J. Am. Chem. Soc. 2009, 132, 922-923. (k) Kreno, L. E.; Hupp, J. T.; Van Duyne, R. P. Anal. Chem. 2010, 82, 8042-8046. (l) Lu, G.; Hupp, J. T. J. Am. Chem. Soc. 2010, 132, 7832-7833.

(13) (a) Hurd, J. A.; Vaidhyanathan, R.; Thangadurai, V.; Ratcliffe, C. I.; Moudrakovski, I. L.; Shimizu, G. K. H. Nat. Chem. 2009, 1, 705710. (b) Sadakiyo, M.; Yamada, T.; Kitagawa, H. J. Am. Chem. Soc. 2009, 131, 9906-9907. (c) Kobayashi, Y.; Jacobs, B.; Allendorf, M. D.; Long, J. R. Chem. Mater. 2010, 22, 4120-4122. (d) Taylor, J. M.; Mah, R. K.; Moudrakovski, I. L.; Ratcliffe, C. I.; Vaidhyanathan, R.; Shimizu, G. K. H. J. Am. Chem. Soc. 2010, 132, 14055-14057. (e) Yamada, T.; Morikawa, S.; Kitagawa, H. Bull. Chem. Soc. Jpn. 2010, 83, 42-48. (f) Shigematsu, A.; Yamada, T.; Kitagawa, H. J. Am. Chem. Soc. 2011, 133, 2034-2036. (g) Jeong, N. C.; Samanta, B.; Lee, C. Y.; Farha, O. K.; Hupp, J. T. J. Am. Chem. Soc. 2012, 134, 51-54. (h) Colodrero, R. M. P.; Olivera-Pastor, P.; Losilla, E. R.; Hernandez-Alonso, D.; Aranda, M. A. G.; Leon-Reina, L.; Rius, J.; Demadis, K. D.; Moreau, B.; Villemin, D.; Palomino, M.; Rey, F.; Cabeza, A. Inorg. Chem. 2012, 51, 7689-7698. (i) Colodrero, R. M. P.; Papathanasiou, K. E.; Stavgianoudaki, N.; Olivera-Pastor, P.; Losilla, E. R.; Aranda, M. A. G.; Leon-Reina, L.; Sanz, J.; Sobrados, I.; Choquesillo-Lazarte, D.; Garcia-Ruiz, J. M.; Atienzar, P.; Rey, F.; Demadis, K. D.; Cabeza, A. Chem. Mater. 2012, 24, 3780-3792. (j) Costantino, F.; Donnadio, A.; Casciola, M. Inorg. Chem. 2012, 51, 6992-7000. (k) Narayan, T. C.; Miyakai, T.; Seki, S.; Dinca, M. J. Am. Chem. Soc. 2012, 134, 1293212935. (1) Perez-Cappe, E.; Aguilar-Frutis, M.; Chavez, N.; Ribalta, J.; Reguera, E. Microporous Mesoporous Mater. 2012, 163, 326-333. (m) Ponomareva, V. G.; Kovalenko, K. A.; Chupakhin, A. P.; Dybtsev, D. N.; Shutova, E. S.; Fedin, V. P. J. Am. Chem. Soc. 2012, 134, 1564015643. (n) Sadakiyo, M.; Okawa, H.; Shigematsu, A.; Ohba, M.; Yamada, T.; Kitagawa, H. J. Am. Chem. Soc. 2012, 134, 5472-5475. (o) Sen, S.; Nair, N. N.; Yamada, T.; Kitagawa, H.; Bharadwaj, P. K. J. Am. Chem. Soc. 2012, 134, 19432-19437. (p) Wu, B.; Lin, X. C.; Ge, 
L.; Wu, L.; Xu, T. W. Chem. Commun. 2013, 49, 143-145. (q) Wei, M.; Wang, X.; Duan, X. Chem.-Eur. J. 2013, 19, 1607-1616. (r) Yoon, M.; Suh, K.; Natarajan, S.; Kim, K. Angew. Chem., Int. Ed. 2013, 52, 2688-2700. (s) Kitagawa, H.; Nagao, Y.; Fujishima, M.; Ikeda, R.; Kanda, S. Inorg. Chem. Commun. 2003, 6, 346-348.

(14) (a) Demessence, A.; D’Alessandro, D. M.; Foo, M. L.; Long, J. R. J. Am. Chem. Soc. 2009, 131, 8784-8786. (b) An, J.; Geib, S. J.; Rosi, N. L. J. Am. Chem. Soc. 2010, 132, 38-39. (c) Ferey, G.; Serre, C.; Devic, T.; Maurin, G.; Jobic, H.; Llewellyn, P. L.; De Weireld, G.; Vimont, A.; Daturi, M.; Chang, J. S. Chem. Soc. Rev. 2011, 40, 550562. (d) Zheng, B. S.; Bai, J. F.; Duan, J. G.; Wojtas, L.; Zaworotko, M. J. J. Am. Chem. Soc. 2011, 133, 748-751. (e) Goeppert, A.; Czaun, M.; Prakash, G. K. S.; Olah, G. A. Energy Environ. Sci. 2012, 5, 7833-7853. (f) Cui, P.; Ma, Y. G.; Li, H. H.; Zhao, B.; Li, J. R.; Cheng, P.; Balbuena, P. B.; Zhou, H. C. J. Am. Chem. Soc. 2012, 134, 1889218895. (g) Park, J.; Yuan, D. Q.; Pham, K. T.; Li, J. R.; Yakovenko, A.; Zhou, H. C. J. Am. Chem. Soc. 2012, 134, 99-102. (h) Yang, S. H.; Lin, X.; Lewis, W.; Suyetin, M.; Bichoutskaia, E.; Parker, J. E.; Tang, C. C.; Allan, D. R.; Rizkallah, P. J.; Hubberstey, P.; Champness, N. R.; Thomas, K. M.; Blake, A. J.; Schröder, M. Nat. Mater. 2012, 11, 710716. (i) Chaemchuen, S.; Kabir, N. A.; Zhou, K.; Verpoort, F. Chem. Soc. Rev. 2013, 42, 9304-9332.

(15) The crystal structure of CA-CDMOF-2 could not be determined from single crystal X-ray diffraction studies as a consequence of high positional disorder of the bound $\mathrm{CO}_{2}$. Instead, we simulated the structure based on CP-MAS ${ }^{13} \mathrm{C}$ NMR $(400 \mathrm{MHz})$ spectroscopic studies. 